\title{
Pengembangan Skill Assesment Keamanan Jaringan
}

\author{
${ }^{1}$ Rochmad Mohammad Thohir Yassin, ${ }^{2}$ Alfian Zakaria \\ 1,2 Jurusan Teknik Informatika, Fakultas Teknik, Universitas Negeri Gorontalo
}

JI. Prof. Dr. Ing. B.J. Habibie Kabupaten, Moutong, Tilongkabila, Bone Bolango, Gorontalo 96119 e-mail: thohir@ung.ac.id

\begin{abstract}
Abstrak
Perkembangan Information and Communication dan Technology (ICT) turut mempengaruhi dunia pendidikan, ICT didorong untuk dapat mendukung jalannya dunia pendidikan sebagai media yang cukup efektif dalam interaksi antara dosen/guru dan mahasiswa tanpa adanya batas ruang dan waktu. Tujuan penelitian ini adalah mengembangkan skill assesment menggunakan perangkat lunak simulasi, meningkatkan pemahaman mahasiswa terhadap setiap materi perkuliahan, meningkatkan kompetensi mahasiswa di bidang keamanan jaringan. Metode yang digunakan dalam penelitian ini adalah metode eksperimen. Hasil penelitian ini adalah dikembangkannya media pembelajaran berupa skill assesment dan prototipe aplikasi pembelajaran berbasis mobile untuk mengukur ketercapaian pembelajaran di bidang keamanan jaringan.
\end{abstract}

Kata kunci: Media Pembelajaran; Assesment; Keamanan Jaringan

\begin{abstract}
The development of Information and Communications Technology (ICT) also influences the education sector, ICT is encouraged to be able to support education as a medium that is quite effective to accommodate interaction between lecturers/teachers and students without the limits of space and time. The purpose of this research is to develop skills assessment using simulation software and to improve student understanding of each lecture material as well as student competency in the field of network security. The method used in this research is the experimental method. The results of the research are the development of learning media in the form of skills assessment and the prototype of a mobile-based learning application to measure learning achievement in the field of network security.
\end{abstract}

Keywords: Learning Media; Assessment; Network Security

Diterima: 21 Juli 2020

Disetujui: 22 Desember 2020

(C)2020 Rochmad Mohammad Thohir Yassin, Alfian Zakaria

Dipublikasi: 29 Desember 2020

Under the license CC BY-SA 4.0

\section{Pendahuluan}

Perkembangan Information, Communication dan Technology (ICT) turut mempengaruhi dunia pendidikan, ICT didorong untuk dapat mendukung jalannya dunia pendidikan sebagai media yang cukup efektif dalam interaksi antara dosen/guru dan mahasiswa/siswa tanpa adanya batas ruang dan waktu. Pengembangan media pembelajaran berbasis ICT sudah banyak dikembangkan antara multimedia pembelajaran (audio dan video) baik yang sifatnya online (bisa diakses di internet) maupun offline, e-learning, virtual class, open courseware. Semua media pembelajaran tersebut adalah fasilitas yang bisa digunakan untuk meningkatkan daya paham mahasiswa/siswa dalam mempelajari materi-materi yang sulit, dapat 
memvisualisasikan konsep-konsep yang sifatnya abstrak, mensimulasikan proses yang sulit dilakukan.

Assessment menurut Asrul, Ananda, \& Rosnita (2015) adalah suatu proses atau kegiatan yang sistematis dan berkesinambungan untuk mengumpulkan informasi tentang proses dan hasil belajar peserta didik dalam rangka membuat keputusankeputusan berdasarkan kriteria dan pertimbangan tertentu. Assesment merupakan salah satu aktivitas dalam evaluasi pembelajaran. Assesment merupakan proses pengumpulan berbagai data yang bisa memberikan gambaran perkembangan belajar mahasiswa (Sugihartini \& Agustini, 2017). Putra, Agustini, \& Santyadiputra (2018) mengungkapkan bahwa tindakan asesmen sangat erat kaitannya dengan pengambilan keputusan. Assesment adalah bagian dari penilaian seperti yang diungkapkan oleh (Dewi \& Rosana, 2017) bahwa penilaian merupakan salah satu proses yang penting sebagai bagian dari pembelajaran. Salah satu bentuk assesment yaitu skill assessment yang dapat digunakan sebagai bahan untuk penilaian dan meningkatkan keterampilan individu peserta didik, dimana melalui media pembelajaran dalam bentuk latihan atau tugas menggunakan software simulasi jaringan pada beberapa pokok bahasan pada mata kuliah keamanan jaringan.

Dalam kaitannya dengan asesmen, Popham dalam (Dantes, 2008) mengatakan bahwa asesmen seringkali dimaksudkan sama dengan evaluasi. Kata asesmen dianggap lebih 'ramah' dibandingkan dengan evaluasi. Setelah dua puluh tahun, (Popham dalam Dantes, 2008) lebih menekankan lagi bahwa pada hakikatnya kata asesmen maupun evaluasi secara prinsip tidaklah berbeda, dan menggunakannya dengan makna yang sama.

Media pembelajaran menurut Santyasa dalam (Sahid, 2007) yaitu segala sesuatu yang dapat digunakan untuk menyalurkan pesan (bahan pembelajaran), sehingga dapat merangsang perhatian, minat, pikiran dan perasaan siswa dalam kegiatan belajar untuk mencapai tujuan pembelajaran. Media pembelajaran menurut Sahid (2007), tidak dapat dipisahkan dari proses pembelajaran. Tanpa media pembelajaran, proses belajar mengajar tidak dapat terjadi. Setiap proses belajar mengajar memerlukan pemilihan dan penggunaan paling tidak satu medium untuk menyampaikan pembelajaran. Syarifuddin \& Sumbawati (2016) pada penelitiannya telah mengembangkan e-Komik sebagai media pembelajaran keamanan jaringan yang berfokus pada materi kriptografi. Penelitian ini fokus kepada kriptografi dan teknologi keamanan jaringan.

Teknologi keamanan jaringan menurut Purbo (2011) yaitu penetration testing yang meliputi firewall, intrusion detection, network authentication, air gap technology, 
authorization. Selain itu salah satu teknologi pada keamanan jaringan yaitu certificate authority termasuk di dalamnya VPN dan Cryptographic Communication, secure web server, single sign on dan lain sebagainya. Dua teknologi keamanan jaringan lain adalah vulnerability testing dan managed security services. Menurut Filkins (2017), teknologi keamanan jaringan meliputi firewall, IDS/IPS (Network dan Host Based), Malware Detection, Secure email gateway, Web Application Firewall dan Cloud access security brokers (CASB). Ma'sum, Irwansyah, \& Priyanto (2017) mengungkapkan bahwa keamanan jaringan adalah proses untuk mencegah dan mengidentifikasi penggunaan yang tidak sah dari jaringan komputer. Ocanitra \& Ryansyah (2019) mendeskripsikan keamanan jaringan merupakan suatu cara atau suatu sistem yang digunakan untuk memberikan proteksi atau perlindungan pada suatu jaringan agar terhindar dari berbagai ancaman luar yang mampu merusak jaringan dan pencurian data perusahaan. Teknologi-teknologi keamanan jaringan ini perlu dipelajari oleh mahasiswa di tengah banyaknya security incident seperti yang dilaporkan oleh Kizza (2014), di mana pencurian informasi pribadi, sabotase pada jaringan, penyalahgunaan jaringan wireless serta trojan atau rootkit masih marak terjadi dan kebutuhan akan tenaga ahli di bidang keamanan jaringan di dunia kerja khususnya bidang teknologi informasi (IT). Untuk mengasah skill mahasiswa terhadap teknologi keamanan jaringan tersebut diperlukan skill assessment untuk menjawab ancaman dan tantangan tersebut.

Mata kuliah keamanan jaringan sendiri baru ditawarkan pada semester ganjil (semester 5) pada tahun akademik 2015/2016 dimana mata kuliah ini ditawarkan kepada mahasiswa program studi S1-Pendidikan Teknologi Informasi. Pada awal mata kuliah ini diajarkan skill assessment belum dikembangkan dan media pembelajaran yang digunakan masih sebatas pada file presentasi (powerpoint) dan bahan ajar (document) serta didukung oleh e-book dalam format $p d f$. Terdapat penurunan peminat mata kuliah ini dari 15 orang mahasiswa di tahun akademik 2015/2016 menjadi hanya 9 orang mahasiswa yang mengontrak mata kuliah ini di tahun akademik 2016/2017 berdasarkan data di Sistem Informasi Akademik Terpadu (SIAT) UNG. Dari hasil pembelajaran diakhir semester di tahun akademik 2015/2016 rata-rata nilai akhir mahasiswa mencapai 84,20 dan angka ini menurun di tahun akademik 2016/2017 dimana rata-rata nilai akhir yaitu 76,36 . Sehingga dari sisi minat dan hasil belajar terhadap mata kuliah keamanan jaringan dapat dikatakan menurun. Bahkan di tahun akademik 2017/2018 hingga 2018/2019 mata kuliah keamanan jaringan tidak diminati sama sekali oleh mahasiswa. Peminat mata kuliah ini baru hadir kembali di tahun 
akademik 2019/2020 di mana terdapat 13 mahasiswa yang mengontrak mata kuliah ini.

Menurunnya peminat dan hasil belajar pada mata kuliah keamanan jaringan ini memerlukan solusi pengembangan media pembelajaran yang lebih mudah digunakan dan dipahami serta diakses oleh mahasiswa. Fokus pada penelitian ini adalah mengembangkan skill assesment menggunakan software simulasi jaringan dan mengembangkan media pembelajaran berbasis aplikasi mobile yang dapat digunakan dengan mudah oleh mahasiswa.

\section{Metode}

Rancangan penelitian ini menggunakan pendekatan eksperimen dikarenakan penelitian eksperimen ini terdapat perlakuan (treatment) yang digunakan untuk mencari pengaruh perlakuan tertentu terhadap yang lain dalam kondisi yang terkendalikan. Tools yang digunakan dalam membuat skill assessment adalah software Cisco Packet Tracer dan tools Learning Management System yang digunakan adalah Moodle dengan alamat URL: http://kuliahdaring.ung.ac.id. Adapun langkah-langkah penelitian ini sebagai berikut:

Analisis Kebutuhan dan Pengumpulan Data

Sebagai langkah awal dari penelitian ini adalah dengan melakukan analisis kebutuhan diantaranya adalah analisis kebutuhan data. Setelah didapatkan maka dilanjutkan dengan pengumpulan data primer. Data primer yang dibutuhkan yaitu beberapa literatur yang terkait dengan keamanan jaringan dan materi-materi perkuliahan yang telah diberikan. Tahapan penelitian yang dilakukan dengan melakukan observasi (pengamatan) secara langsung. Keluaran dari tahapan penelitian ini diperolehnya data-data primer penelitian. Indikator keberhasilan dari tahapan penelitian ini adalah terkumpulnya data primer penelitian.

Perancangan skill assesment

Dari hasil pengumpulan data primer maka langkah selanjutnya dirancang media pembelajaran berupa skill assesment. Keluaran dari tahapan penelitian ini adalah rancangan media pembelajaran dalam bentuk skill assesment. Indikator keberhasilan dari tahapan penelitian ini adalah terbuatnya rancangan media pembelajaran dalam bentuk skill assesment.

Pembuatan skill assesment

Pada tahap ini dibuatnya media pembelajaran berupa skill assesment. Pembuatan skill assessment ini mengacu pada rancangan skill assessment yaitu mulai dari menentukan author, menentukan instruksi soal, menentukan kunci jawaban, menentukan item-item jawaban, menentukan topologi yang belum terjawab hingga 
mengetes activity dan menyimpan file. Keluaran dari tahapan ini adalah media pembelajaran berupa skill assesment. Indikator keberhasilan dari tahapan penelitian ini adalah terciptanya skill assessment yang dapat dipahami dan digunakan dengan mudah oleh mahasiswa.

Pengujian

Pada tahapan penelitian ini, aktivitas yang dilakukan adalah menguji skill assesment yang telah dibuat. Pengujian skill assesment untuk mengukur sejauh mana pemahaman materi perkuliahan yang diberikan sebelumnya. Keluaran dari tahapan penelitian ini adalah skill assesment yang telah teruji. Indikator keberhasilan tahapan penelitian ini adalah semua skenario yang telah ditentukan dalam pengujian terlaksana dengan baik.

\section{Hasil dan Pembahasan}

Hasil

Berdasarkan langkah-langkah penelitian, maka tahapan pertama dari penelitian ini adalah analisis kebutuhan terhadap penelitian ini, dari analisis kebutuhan tersebut ditetapkan bahwa diperlukan Rencana Pembelajaran Semester (RPS) mata kuliah keamanan jaringan karena skill assessment yang dikembangkan haruslah mengacu pada panduan ini. Sebagai penunjangnya maka diperlukan literatur tentang keamanan jaringan. Dari hasil analisis kebutuhan juga ditetapkan diperlukan pengembangan skill assesment pada software simulasi jaringan dan pengembangan aplikasi pembelajaran keamanan jaringan berbasis mobile. Skill assesment yang telah dikembangkan perlu diterapkan pada salah satu Learning Management System (LMS) UNG. Data yang telah dikumpulkan berupa RPS mata kuliah keamanan jaringan dan beberapa literatur (e-book) dan lecture notes and reading dari open courseware Massachusetts Institute of Technology (MIT) yaitu Network and Computer Security.

Diantara salah satu kompetensi dari mata kuliah keamanan jaringan adalah mahasiswa mampu menjelaskan tentang teknologi keamanan jaringan, pengembangan skill assessment harus memenuhi kompetensi tersebut. Tahapan penelitian berikutnya yaitu perancangan skill assessment, perancangan yang pertama yaitu skill assessment pada software simulasi jaringan dimana rancangan langkahlangkah skill assesment yang dibuat seperti yang terlihat pada gambar 1 . 


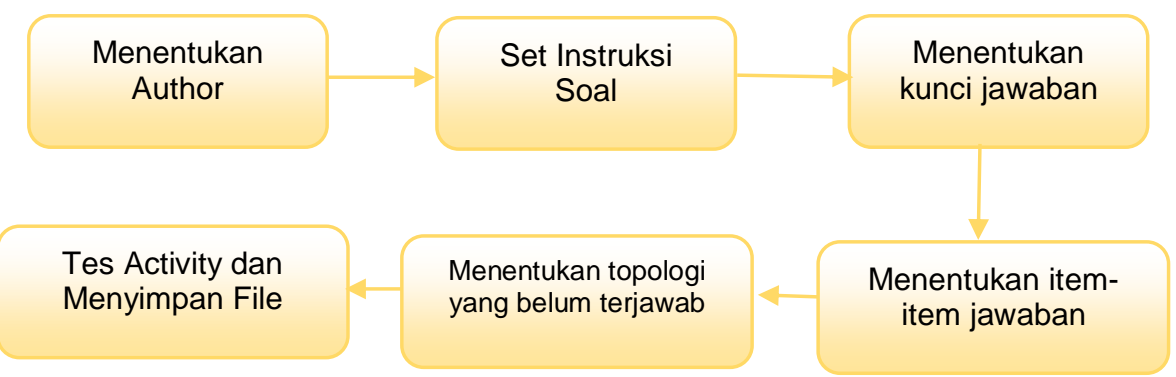

Gambar 1 Rancangan skill assesment pada software simulasi jaringan

Rancangan kedua yaitu flowchart sistem media pembelajaran dalam bentuk aplikasi berbasis mobile seperti terlihat pada gambar 2 .

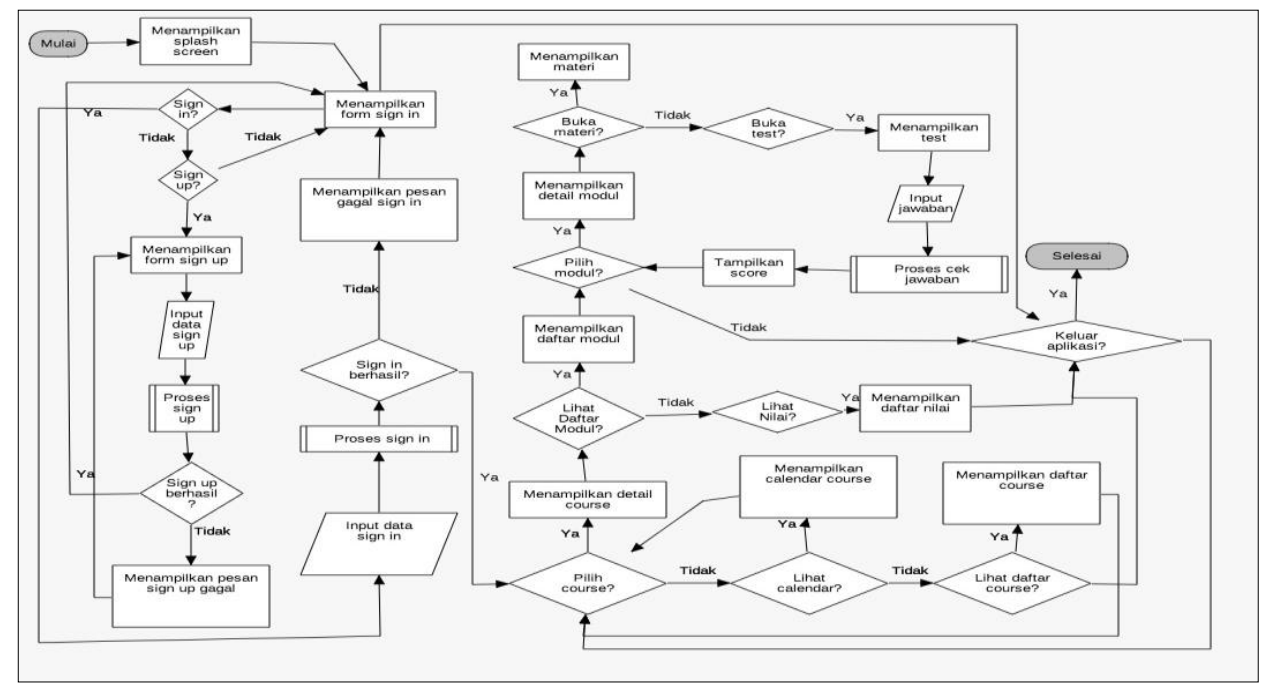

Gambar 2 Rancangan sistem aplikasi pembelajaran keamanan jaringan

Pembuatan skill assesment berdasarkan pada rancangan skill assesment dapat dilihat pada gambar 3 .

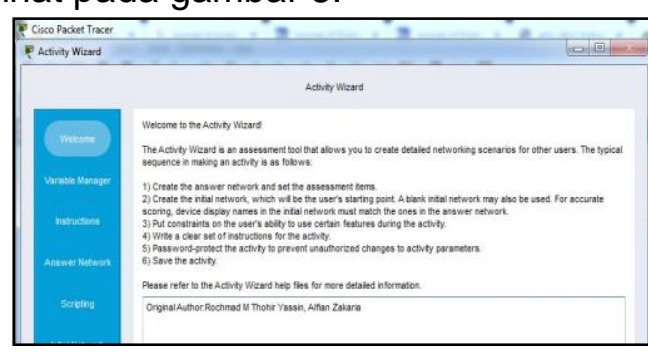

(a) Menentukan author

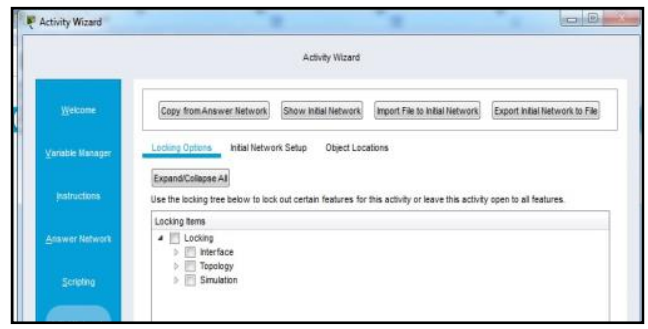

(c) Menentukan kunci jawaban

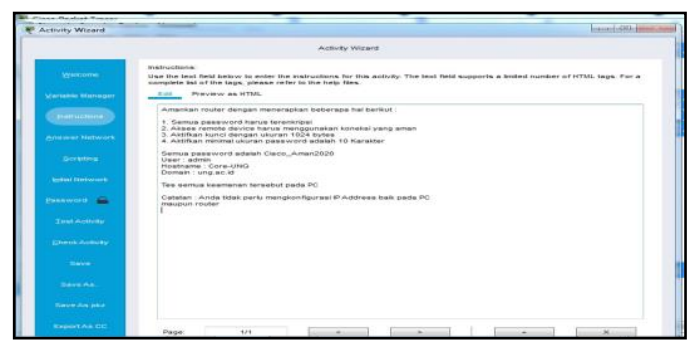

(b) Membuat instruksi soal

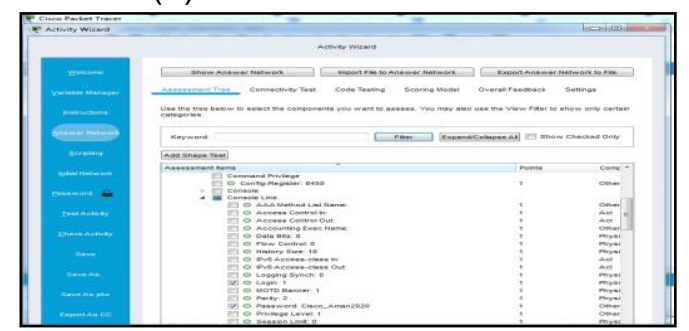

(d) menentukan item-item jawaban dan topologi yang belum terjawab 


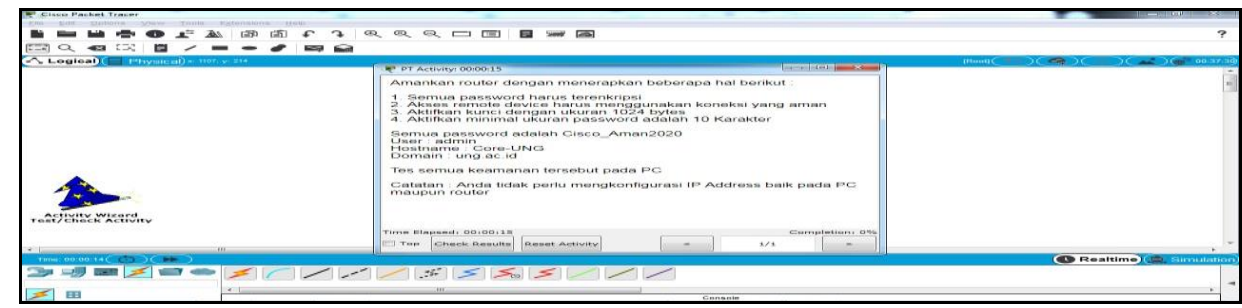

(e) Menguji skill assesment dan menyimpan file skill assesment

Gambar 3 Pembuatan skill assesment pada software simulasi jaringan

Pada gambar 3 dapat dilihat urutan pembuatan skill assesment mulai dari (a) menentukan author, (b) membuat instruksi soal, (c) menentukan kunci jawaban, (d) menentukan item-item jawaban dan topologi yang belum terjawab, (e) Menguji skill assesment dan menyimpan file skill assesment tersebut.

Salah satu skill assessment yang telah dibuat pada gambar 3 dapat dilihat dari gambar 4.

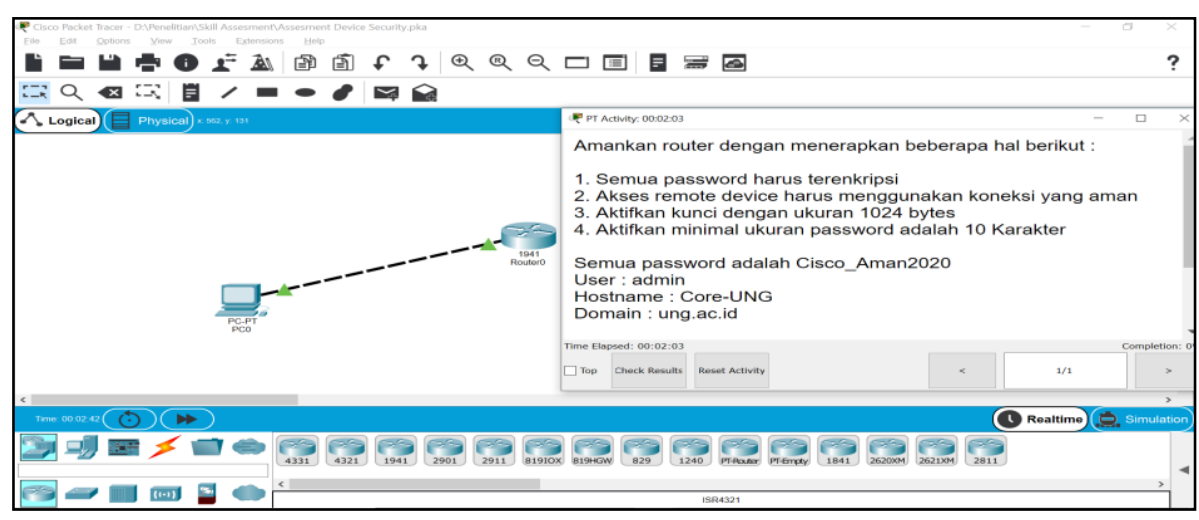

Gambar 4 Skill assessment yang telah dibuat

Dari gambar 4 dapat dijelaskan bahwa disetiap aktivitas terdapat completion (score) dengan nilai berupa presentase. Dimana jika setiap item soal yang dikerjakan dengan benar maka akan bertambah nilai presentasenya. Mahasiswa dapat melihat item yang dikerjakan sudah benar atau tidak dapat menekan tombol check results.

Hasil uji dari beberapa skill assesment yang telah dibuat pada software simulasi jaringan dapat ditunjukkan pada tabel 1.

Tabel 1 Pengujian Skill Assesment

\begin{tabular}{|c|c|c|c|c|}
\hline No. & Nama Skill Assesment & $\begin{array}{c}\text { Assesment } \\
\text { Item }\end{array}$ & $\begin{array}{l}\text { Total } \\
\text { Score }\end{array}$ & Keterangan \\
\hline 1. & Device Security & 25 & $96 \%$ & $\begin{array}{l}\text { Terdapat } 1 \text { item yang dikerjakan } \\
\text { dengan benar tapi dianggap salah }\end{array}$ \\
\hline 2. & Firewall (Standard)-1 & 2 & $100 \%$ & \\
\hline 3. & Firewall (Extended)-1 & 2 & $100 \%$ & \\
\hline 4. & Firewall (Standard)-2 & 14 & $100 \%$ & \\
\hline 5. & Firewall (Extended)-2 & 54 & $100 \%$ & \\
\hline 6. & Firewall (Named) & 25 & $100 \%$ & \\
\hline 7. & Firewall (NAT Statis) & 18 & $88 \%$ & Terdapat 2 item routing statis \\
\hline
\end{tabular}




\begin{tabular}{llccl}
\hline No. & Nama Skill Assesment & $\begin{array}{c}\text { Assesment } \\
\text { Item }\end{array}$ & $\begin{array}{c}\text { Total } \\
\text { Score }\end{array}$ & \multicolumn{1}{c}{ Keterangan } \\
\hline & & & $\begin{array}{l}\text { dikerjakan dengan benar tapi } \\
\text { dianggap salah }\end{array}$ \\
8. & Wireless Security & 36 & $100 \%$ & \\
9. & Virtual Private Network & 12 & $100 \%$ & \\
(VPN) & Intrusion Prevention & 30 & $100 \%$ & \\
10. & System (IPS) & & & \\
\hline
\end{tabular}

Dari tabel 1 dapat dilihat terdapat dua skill assesment dimana total score (completion) yang tidak mencapai nilai 100\% karena ada item jawaban yang sudah sesuai dengan instruksi soal namun dianggap tidak benar oleh software simulasi jaringan.

Sebagai penunjang dari proses pembelajaran pada mata kuliah keamanan jaringan, dikembangkan prototipe media pembelajaran berupa aplikasi pembelajaran keamanan jaringan berbasis mobile dengan platform android dapat dilihat pada gambar 5 .

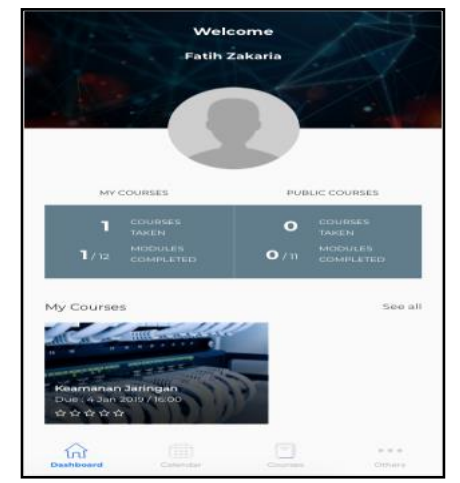

(a) Beranda

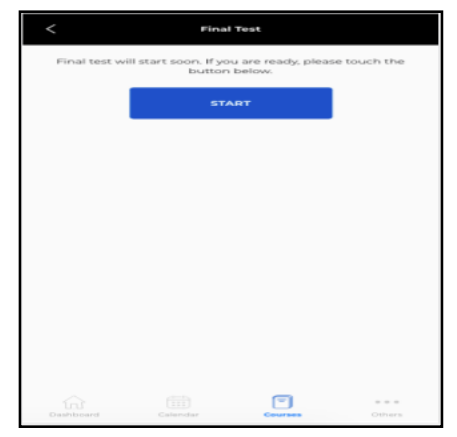

(d) Memulai Test

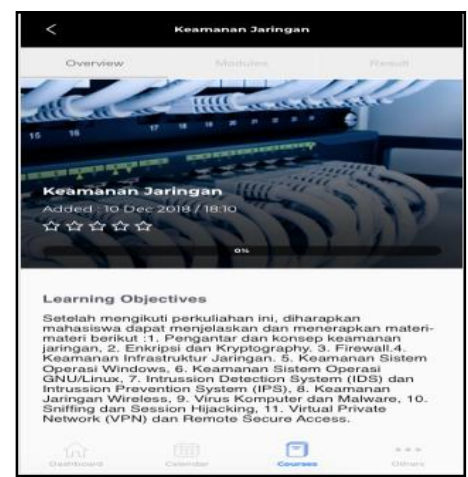

(b) Deskripsi Mata Kuliah

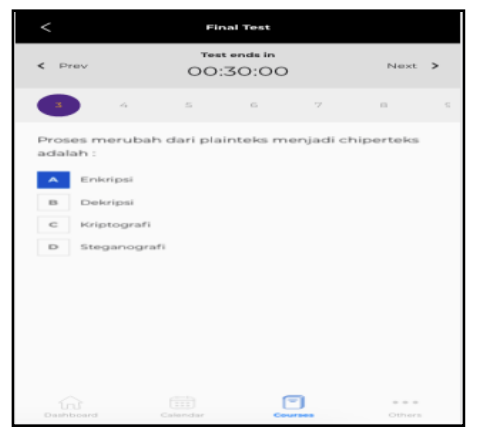

(e) Soal

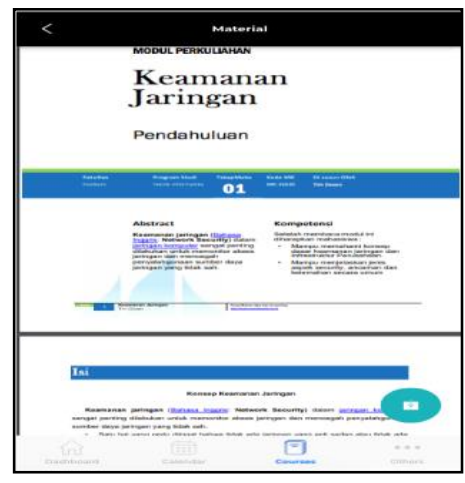

(c) Materi

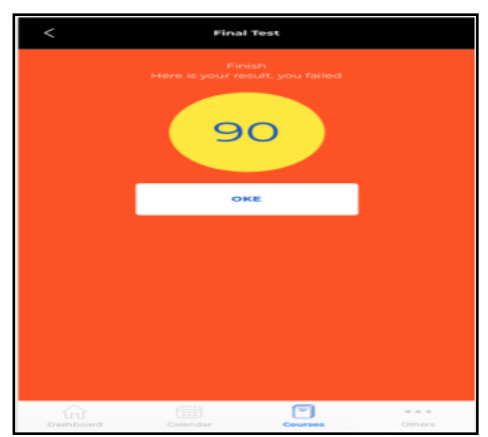

(f) Nilai

Gambar 5 Prototipe aplikasi pembelajaran keamanan jaringan 
Dilakukan blackbox-testing pada prototipe aplikasi pembelajaran keamanan jaringan berbasis mobile dengan hasil seperti terlihat pada Tabel 2 dan 3.

Tabel 2 Hasil Blackbox-Testing Halaman Login

\begin{tabular}{cllcc}
\hline No & Skenario Pengujian & Hasil yang diharapkan & $\begin{array}{c}\text { Hasil } \\
\text { pengujian }\end{array}$ & Kesimpulan \\
\hline 1. $\begin{array}{l}\text { Email dan password } \\
\text { tidak diisi kemudian } \\
\text { klik tombol login }\end{array}$ & $\begin{array}{l}\text { Sistem tidak } \\
\text { menampilkan menu }\end{array}$ & $\begin{array}{c}\text { Sesuai } \\
\text { harapan }\end{array}$ & Valid \\
$\begin{array}{l}\text { Menginputkan email } \\
\text { dan password dengan } \\
\text { salah }\end{array}$ & $\begin{array}{l}\text { Sistem tidak } \\
\text { menampilkan menu }\end{array}$ & $\begin{array}{c}\text { Sesuai } \\
\text { harapan }\end{array}$ & Valid \\
$\begin{array}{l}\text { Menginputkan email } \\
\text { dan password dengan } \\
\text { benar }\end{array}$ & $\begin{array}{l}\text { Sistem menampilkan } \\
\text { menu utama }\end{array}$ & $\begin{array}{l}\text { Sesuai } \\
\text { harapan }\end{array}$ & Valid \\
\hline
\end{tabular}

Tabel 3 Hasil Blackbox-Testing Menu Discussion

\begin{tabular}{|c|c|c|c|c|}
\hline No & Skenario Pengujian & Hasil yang diharapkan & $\begin{array}{c}\text { Hasil } \\
\text { pengujian }\end{array}$ & Kesimpulan \\
\hline 1. & $\begin{array}{l}\text { Title dan Message } \\
\text { tidak diisi kemudian } \\
\text { klik tombol submit }\end{array}$ & $\begin{array}{l}\text { Sistem menampilkan } \\
\text { pesan : "Enter the title } \\
\text { and message first" }\end{array}$ & $\begin{array}{l}\text { Sesuai } \\
\text { harapan }\end{array}$ & Valid \\
\hline 2. & $\begin{array}{l}\text { Title diisi dan Message } \\
\text { tidak diisi kemudian } \\
\text { klik tombol submit }\end{array}$ & $\begin{array}{l}\text { Sistem menampilkan } \\
\text { pesan : "Enter the title } \\
\text { and message first" }\end{array}$ & $\begin{array}{l}\text { Sesuai } \\
\text { harapan }\end{array}$ & Valid \\
\hline 3. & $\begin{array}{l}\text { Title tidak diisi dan } \\
\text { Message diisi } \\
\text { kemudian klik tombol } \\
\text { submit }\end{array}$ & $\begin{array}{l}\text { Sistem menampilkan } \\
\text { pesan : "Enter the title } \\
\text { and message first" }\end{array}$ & $\begin{array}{c}\text { Sesuai } \\
\text { harapan }\end{array}$ & Valid \\
\hline 4. & $\begin{array}{l}\text { Title diisi dan Message } \\
\text { diisi kemudian klik } \\
\text { tombol submit }\end{array}$ & $\begin{array}{l}\text { Sistem menampilkan } \\
\text { title dan message yang } \\
\text { diisi }\end{array}$ & $\begin{array}{l}\text { Sesuai } \\
\text { harapan }\end{array}$ & Valid \\
\hline
\end{tabular}

Dari hasil belajar mahasiswa di tahun akademik 2019/2020 rata-rata nilai akhir mahasiswa mencapai angka 80.88 dan rata-rata nilai tugas dimana skill assessment ini banyak diberikan mencapai angka 80. Akses mahasiswa terhadap konten e-Learning baik di SIAT maupun di LMS kuliah daring terlihat cukup signifikan terutama pada konten materi maupun pada skill assessment. Dari sepuluh skill assessment yang diberikan kepada mahasiswa rata-rata total score yang diperoleh adalah $88 \%$ dan waktu rata-rata penyelesaian setiap skill assessment 35-45 menit dari 60 menit waktu yang diberikan kepada setiap mahasiswa.

\section{Pembahasan}

Mata kuliah keamanan jaringan ini ditawarkan kepada mahasiswa program studi Pengantar Teknologi Informasi (PTI) Jurusan Teknik Informatika sejak tahun akademik 2015/2016, proses pembelajaran lebih banyak didukung oleh Learning Management System (LMS) Sistem Informasi Akademik Terpadu (SIAT). Sejak dikembangkan LMS yang baru yaitu LMS kuliah daring (http://kuliahdaring.ung.ac.id) berbasis moodle, skill 
assesment yang telah dibuat beserta konten e-Learning lainnya diterapkan dalam LMS tersebut.

Selain diterapkan ke LMS, untuk memfasilitasi mahasiswa yang banyak menggunakan perangkat mobile khususnya platform android, materi perkuliahan dan tes (quiz dan ujian) juga tersedia di aplikasi pembelajaran berbasis mobile yang masih berupa prototipe, namun secara umum fitur-fitur untuk proses pembelajaran sudah tersedia pada prototipe aplikasi pembelajaran tersebut.

Ada sepuluh skill assesment yang telah dibuat seperti terlihat pada tabel 1. Setiap skill assesment terdapat assesment item yang khusus dimana setiap assessment item memiliki point penilaian sendiri sesuai dengan kompetensi di setiap pokok bahasan seperti yang terlihat pada tabel 4.

Tabel 4 Assesment item dan Point Assesment

\begin{tabular}{|c|c|c|}
\hline No. & Nama Skill Assesment & Assesment Item \& Point Assesment \\
\hline 1. & Device Security & $\begin{array}{l}\text { Console Security ( } 2 \text { point), Privileged password (1 } \\
\text { point), Secure Connection (19 point), } \\
\text { Security Policy ( } 1 \text { point) }\end{array}$ \\
\hline 2. & Firewall (Standard)-1 & Standard Access List (2 point) \\
\hline 3. & Firewall (Extended)-1 & Extentend Access List (2 point) \\
\hline 4. & Firewall (Standard)-2 & $\begin{array}{l}\text { IP Configuration ( } 11 \text { point), Standard Access List ( } 2 \\
\text { point) }\end{array}$ \\
\hline 5. & Firewall (Extended)-2 & $\begin{array}{l}\text { Extended ACL ( } 1 \text { point), Access Group ( } 2 \text { point VLAN } \\
\text { (5 point), InterVLAN Routing ( } 5 \text { point), Port } \\
\text { Configuration ( } 12 \text { point), Email Client Configuration ( } 8 \\
\text { point), IP Configuration ( } 21 \text { point) }\end{array}$ \\
\hline 6. & Firewall (Named) & $\begin{array}{l}\text { Named ACL ( } 2 \text { point), Access Group ( } 2 \text { point), IP } \\
\text { Configuration ( } 21 \text { point) }\end{array}$ \\
\hline 7. & Firewall (NAT Statis) & $\begin{array}{l}\text { NAT Rule }(2 \text { point), Static Routing }(2 \text { point), IP } \\
\text { Address Configuration ( } 12 \text { point), Hostname ( } 1 \text { point) } \\
\text { Basic Wireless Configuration ( } 3 \text { point }) \text {, Wireless }\end{array}$ \\
\hline 8. & Wireless Security & $\begin{array}{l}\text { Security Configuration ( } 7 \text { point), Wireless Client } \\
\text { Configuration ( } 21 \text { point), IP Address configuration ( } 5 \\
\text { point) }\end{array}$ \\
\hline 9. & $\begin{array}{c}\text { Virtual Private Network } \\
\text { (VPN) }\end{array}$ & Tunnel Configuration (12 point) \\
\hline 10 & $\begin{array}{l}\text { Intrusion Prevention } \\
\text { System (IPS) }\end{array}$ & $\begin{array}{l}\text { IP Configuration (17 point), Static Routes (2), IPS } \\
\text { Configuration (11 point) }\end{array}$ \\
\hline
\end{tabular}

\section{Kesimpulan}

Pengembangan skill assesment berhasil dibuat dengan menggunakan software simulasi jaringan dengan mengacu pada kompetensi dasar yang disusun pada rancangan pembelajaran semester. Skill assesment ini dibuat untuk meningkatkan pemahaman mahasiswa tidak hanya pada teori-teori keamanan jaringan itu sendiri melainkan juga diasah skill untuk dapat mengkonfigurasi teknologi keamanan jaringan. Hal ini secara otomatis juga meningkatkan kompetensi mahasiswa di bidang keamanan jaringan. 
Penelitian menunjukan terdapat 10 skill assesment yang telah dibuat dan berada pada 3 pokok bahasan mata kuliah keamanan jaringan khususnya pada teknologi keamanan jaringan dan eksploitasi sistem dan kejahatan komputer. Hasil pengujian dari skill assesment yang telah dibuat menggunakan software simulasi jaringan tidak sepenuhnya memiliki nilai maksimal (100\% completion) terdapat dua skill assesment yang nilai maksimalnya adalah $88 \%$ dan $96 \%$. Setiap skill assesment yang dibuat memiliki point penilaian sesuai dengan kompetensi yang ada pada setiap pokok bahasan.

Semua konten pembelajaran mata kuliah jaringan juga dapat diakses pada LMS UNG. Selain dapat diakses pada LMS UNG konten pembelajaran juga tersedia pada Prototipe aplikasi pembelajaran mata kuliah keamanan jaringan yang dibuat sebagai pendukung dari kegiatan proses pembelajaran secara daring. Prototipe aplikasi tersebut sudah melalui pengujian menggunakan metode blackbox-testing walaupun belum semua modul yang diuji.

\section{Daftar Pustaka}

Asrul, Ananda, R., \& Rosnita. (2015). Evaluasi Pembelajaran. Bandung: Citapustaka Media.

Dantes, N. (2008). Hakikat Asesmen Otentik Sebagai Penilaian Proses dan Produk Dalam Pembelajaran Yang Berbasis Kompetensi. Denpasar: Universitas Pendidikan Ganesha Singaraja.

Dewi, D. S., \& Rosana, D. (2017). Pengembangan Instrumen Penilaian Kinerja untuk Mengukur Sikap Ilmiah. Jurnal Kependidikan, 1(1), 67-83.

Filkins, B. (2017). Network Security Infrastructure and Best Practices : A SANS Survey. SANS Institute.

Kizza, J. M. (2014). Computer Network Security and Cyber Ethics. North Carolina: McFarland \& Company, Inc.

Ma'sum, M. S., Irwansyah, M. A., \& Priyanto, H. (2017). Analisis Perbandingan Sistem Keamanan Jaringan Menggunakan Snort dan Netfilter. Jurnal Sistem dan Teknologi Informasi (JUSTIN), 5(1), 56-59.

Ocanitra, R., \& Ryansyah, M. (2019). Implementasi Sistem Keamanan Jaringan Menggunakan Firewall Security Port pada Vitaa Multi Oxygen. Jurnal Sistem dan Teknologi Informasi, 7(1), 52-59.

Purbo, O. W. (2011). Keamanan Jaringan. Jakarta.

Putra, P. G., Agustini, K., \& Santyadiputra, G. S. (2018). Pengembangan Asesmen Kinerja dalam Konteks Pembelajaran Administrasi Jaringan Kelas XI TKJ di 
SMK TI Bali Global Singaraja. Kumpulan Artikel Mahasiswa Pendidikan Teknik Informatika (KARMAPATI), 7(2), 59-65.

Sahid. (2007). Pengembangan Media Pembelajaran Berbasis ICT. Retrieved from http://staff.uny.ac.id/sites/default/files/131930136/Pengembangan\%20Media\% 20Pembelajaran\%20Berbasis\%20ICT.pdf.

Sugihartini, N., \& Agustini, K. (2017). Asesmen Otentik sebagai Pendukung Desain Instruksional Jaringan Komputer Berstrategi Blended Learning dengan Pendekatan Konstruktivistik. Journal of Education Research and Evaluation, 1(2), 82-90.

Syarifuddin, M. H., \& Sumbawati, M. S. (2016). Pengembangan e-Komik Sebagai Media Pembelajaran Keamanan Jaringan Materi Kriptografi. Jurnal IT-Edu, 01(01), 30-36. 